\title{
MIGRAÇÃO HAITIANA PARA O BRASIL: QUANDO MUDA A PAISAGEM RACIAL E O "EU" E "OUTRO" SE CONFRONTAM NAS MÍDIAS E REDES SOCIAIS DIGITAIS
}

\author{
Maristela Abadia Guimarães - PPGE - UFMT \\ Estudante Doutorado \\ Kátia Morosov Alonso - PPGE - UFMT \\ Orientadora
}

\section{RESUMO}

A história da migração no Brasil foi percebida como processo social motivada pelo pensamento social brasileiro de cunho racialista, categorizando a migração como seletiva e restritiva: o Brasil seleciona um perfil para receber e aponta outro como "indesejado". Realizada no ciberespaço com o método da netnografia, sendo a internet veículo processador de mudanças sociais e profícua para pesquisas em todas as áreas, levantamos, nas mídias UOL, G1, Folha de São Paulo e redes sociais Facebook e Twitter, manifestações discursivas de brasileiros feitas a partir de 2010 sobre o novo contingente migratório que provocou mudanças na paisagem racial. Como se apresentam as condições de existência no Brasil do "outro", migrante, negro, de um País pobre, Haiti? Confrontamos o "eu", brasileiro, o "outro", haitiano. O racismo e a xenofobia, motivados pelo ódio ao migrante negro, adquiriram novos contornos, recrudesceram e se re-velaram. A transformação da paisagem racial brasileira coloca por terra uma política duramente perseguida ao longo dos séculos e nos faz adentrar o terceiro milênio como uma nação negra, implicando em tons das manifestações que desmistificam o Brasil cordial. Há um "outro", que é negro, migrante, pobre, e contra ele se lançam a intolerância, o ódio e a desumanidade.

Palavra-Chave: Migração Haitiana. Pensamento Social Brasileiro. Mídias e Redes Sociais.

\section{MIGRAÇÃO BRASILEIRA: SELETIVA E RESTRITIVA}

Este estudo é parte da tese de doutorado em Educação [em andamento] desenvolvida no Programa de Pós-Graduação em Educação, pela Universidade Federal de Mato Grosso, no grupo de pesquisa: Laboratório de Estudos sobre Tecnologia da Informação e Comunicação na Educação, Lêtece-UFMT, vinculado ao Projeto "Aprender e ensinar com as TDIC: sobre tendências, dilemas e perspectivas", objetiva analisar as manifestações de brasileiros em determinadas mídias e redes sociais digitais referentes à presença de migrantes haitianos com foco na história do pensamento social brasileiro. A escolha quem quero no país onde vivo nos auxiliará pensar as expressões contidas nos discursos, por que eles são motivados e como são.

A compreensão do Pensamento Social Brasileiro com interface no processo de racialização que atravessou o Brasil desde o século XIX, quando foram incentivadas migrações da Europa para cá, dão mostras de se ter forjado um comportamento seletivo e restritivo que orientou as políticas migratórias no País, cujos reflexos perduram ainda 


\section{SEMINÁRIO DE PESQUISA EM CIÊNCIAS HUMANAS - SEPECH \\ Humanidades, Estado e desafios didático-científicos \\ Londrina, 27 a 29 de julho de 2016}

no século XXI, e dita posturas discriminatórias contra a população negra que vêm para o Brasil, seja ela do Caribe, seja da África.

A migração é processo corresponsável para a construção do ideário de nação brasileira: que tipo de nação se queria? A migração, portanto, configurou-se como amplo aspecto para o processo civilizatório brasileiro e condição para o País se tornasse nação. Iniciada ainda no alvorecer da colonização com a chegada dos portugueses e holandeses, preponderando a permanência dos primeiros, e seguida pela migração forçada de africanos na situação de escravizados, e continuada no incentivo à vinda de migrantes europeus já no final do século XIX, a busca pela seleção de quais indivíduos se desejava para construir o "tipo brasileiro" já se fazia perceber naquele século e se mantém atualmente.

Um percurso pelo processo migratório brasileiro explicita restrições nas legislações brasileiras em diferentes momentos. Com um olhar voltado para a história do pensamento social brasileiro, verificamos que "a questão racial esteve subjacente aos projetos imigrantistas desde 1818, antes ainda de a palavra raça fazer parte do vocabulário científico brasileiro e das preocupações com a formação nacional" (SEYFERTH; 2002, p. 118).

A pesquisa refez o percurso histórico da migração brasileira nacional e internacional a partir do séc. XIX, passando pelo XX e adentrando o XXI. Foram percorridos, nessa trajetória, 4 períodos históricos para a migração brasileira: 1. de 1870, auge da entrada de migrantes subvencionados pelo Estado brasileiro, até 1930; 2. de 1930 a 1980, os deslocamentos internos, com maior mobilidade entre 30 a 1950 e o declínio do quantitativo de estrangeiros ${ }^{1}$ em território brasileiro, fruto das ditaduras Vargas e Militar, bem como o impedimento da entrada de "indesejáveis"; 3. de 1980 a 2010, a saída de brasileiros para outros países, consequência das crises econômicas vivenciadas pelo Brasil, cujo apogeu se deu nos anos de 1980 e reingresso, a partir de 2008, com a crise econômica na América do Norte e Europa e, por fim, 4. a partir de 2010, quando se verifica o novo panorama migratório no Brasil.

Essa releitura é relevante porque as legislações brasileiras que atualmente regulamentam a migração não são recentes, parte delas advieram do século XX. Por conseguinte, não é possível falar em migração contemporânea brasileira sem passar pela compreensão dos processos históricos, considerando que ainda se está à luz de normas datadas do século passado, como a Lei $\mathrm{n}^{\circ} 6.815 / 80$, em vigor, que dispõe sobre entrada e permanência do estrangeiro no Brasil baseada na segurança e no interesse nacional.

O Brasil, historicamente, carrega traços seletivos em sua política migratória, adotando esse posicionamento para a recepção de migrantes. Esse processo, antes de ser político, é social, posto que advenha de uma postura que se conforma com o desejo de se ter no País uma paisagem racialmente construída nos moldes europeus, sobretudo quando se observa como se configurou a migração no século XIX e início do seguinte.

Encetou-se de 1870 a 1930 a vinda de cerca de 40 milhões de pessoas para o Brasil, atraídos pelas ofertas de trabalho nas lavouras e indústrias do Sudeste do País, expressiva maioria oriunda da Europa Ocidental que para cá se dirigiram apoiados por políticas de Estado.

\footnotetext{
${ }^{1}$ Chamamos estrangeiro em conformidade com Lei $\mathrm{n}^{\mathrm{o}} 6.815 / 80$, em vigor, que dispõe sobre entrada e permanência do estrangeiro no Brasil; baseada na segurança e no interesse nacional. Em seu corpus, ao tratar os migrantes como estrangeiro age de forma discriminatória.
} 


\section{SEMINÁRIO DE PESQUISA EM CIÊNCIAS HUMANAS - SEPECH \\ Humanidades, Estado e desafios didático-científicos \\ Londrina, 27 a 29 de julho de 2016}

A ideia era de que a América "se forjasse pelo melting Pot e brancos" (SEYFERTH, 2015, p.24). De acordo com a autora, essa noção constituída no século XVIII continha o ideal iluminista e primava pela noção de que "se poderia fazer na América um país que reunisse diferentes nacionalidades europeias em harmonia e que elas pudessem se misturar nos dois sentidos, ou seja, cultural e físico (SEYFERTH, 2015, p.24, grifos nossos). Assim, o termo passa a ser apropriado no Brasil para "justificar e consolidar o ideal de mestiçagem" (ibidem). Justificando, também, a necessidade de incentivar a política migratória de europeus.

De tal modo, a nascente política migratória era conduzida: de maneira a se pensar numa construção sociorracial para o povo brasileiro, de nação que mais tardiamente rompeu com a escravidão, para uma nação que importava mão de obra europeia para a edificação de uma sociedade civilizada nos moldes europeus. Desse modo, "a promoção da imigração européia, teria a dupla vantagem de trazer o trabalho livre e o influxo 'purificador' da raça branca" (GORENDER, 1990, p. 163, grifos do autor). Como consequência, a imigração é vista como "uma forma de civilizar (SEYFERTH, 2015, p 48), somente por meio desse processo seria possível criar uma nação, e se constituir uma classe média, num projeto liberal.

De 1881 a 1902, a migração para as lavouras cafeeiras paulistas foi subvencionada pelo governo, vindo para a região italianos, portugueses e espanhóis, muitos depois se dirigiram para São Paulo devido à industrialização. A partir de 1908, o governo também subvencionou a vinda de japoneses para a mesma região com o mesmo objetivo, e muitos destes também fizeram o percurso para a zona urbana. Em 1901, estrangeiros constituíam 92\% dos trabalhadores nas indústrias de São Paulo.

A diferença entre as migrações, a subvencionada pelo Estado e a forçada, ao longo dos séculos, vai colaborar para a construção do pensamento social brasileiro. A primeira considerada como aquela que superou barreiras e ascendeu socialmente; a segunda vista como aquela que não conseguiu ascensão social. São esses os moldes com que se construiu o imaginário racista do brasileiro sobre o negro, não levando em conta o contexto histórico do final do século XIX e durante todo o século XX.

Adentrando os anos 30 do século XX, o Brasil publica medidas restritivas à entrada de imigrantes internacionais no Brasil (PATARRA, 2012; PATARRA e FERNANDES, 2011). As restrições se ampliam e as constituições de 1934 e 1937 fixam cotas para as entradas de estrangeiros para impedir "indesejáveis", em consonância com os novos ideais de sociedade e do nacionalismo propostos pelo Estado Novo e conjugados nas constituições da Era Vargas, quando são circunscritas medidas para a entrada de estrangeiros e criadas novas leis (Constituições de 1934 e 1937) que dispunham sobre os direitos de nacionalidade, cidadania e garantias individuais. A partir desse momento, modifica-se o panorama da migração no Brasil.

O período de 1930 a 1980 pode ser considerado híbrido no contexto migratório: trata-se de um período onde são constantes os movimentos internos no País, a partir, principalmente, do Nordeste para o Sul; a entrada de estrangeiros reduz-se; e se tem início um grande fluxo de saída de brasileiros para destinos internacionais. Desse modo, o processo migratório no século XX foi de pouca entrada e grandes saídas, apoiado por políticas restritivas de entrada, como estabelecido no Decreto-Lei $\mathrm{n}^{\circ} 406$, de 4 de maio de 1938 que, além de impedir a entrada de "aleijados ou mutilados, inválidos, cégos, surdos-mudos, indigentes, vagabundos e congêneres", explicitava e dava plenos poderes ao governo federal para, conforme artigo $2^{\circ}$. "limitar ou suspender, por motivos 


\section{SEMINÁRIO DE PESQUISA EM CIÊNCIAS HUMANAS - SEPECH \\ Humanidades, Estado e desafios didático-científicos \\ Londrina, 27 a 29 de julho de 2016}

econômicos ou sociais, a entrada de indivíduos de determinadas raças ou origens, ouvido o Conselho de Imigração e Colonização" (grifos nossos).

Póvoa Neto (2012), fazendo uma correlação entre o ontem e hoje, diz:

Durante cem anos, até meados do século XX, o país foi polo de atuação dos imigrantes, principalmente europeus, mas também japoneses e árabes. Por causa da Segunda Guerra Mundial, esse processo foi interrompido e, quando a guerra acabou, houve uma retomada das migrações. Até meados nos anos 1960, o Brasil ainda recebia imigrantes. Nos anos 1980 e 1990, o país começou a receber uma imigração muito diferente daquela que havia antes da Segunda Guerra Mundial, porque não era mais de europeus, e sim de sulamericanos, com destaque para os bolivianos, argentinos, paraguaios e peruanos e, posteriormente, os asiáticos, mas não mais os japoneses, e sim os chineses e sul-coreanos. Em menor número, também os africanos. Esse perfil se mantém até agora. A imigração de hoje é muito menor do ponto de vista quantitativo (PÓVOA NETO, Entrevista ao INSTITUTO HUMANITAS UNISINOS, 16 de maio 2012).

Observa-se que o fenômeno migratório no Brasil é bastante complexo, posto não haver sazonalidade, bem como o aspecto quantitativo atual já não mais se equipara ao período de transição entre os séculos XIX e XX. No entanto, a chegada de migrantes haitianos no Brasil pareceu causar estranhamento em parcela da população brasileira, o qual foi, em grande medida, impulsionado pelas mídias e redes sociais digitais. A análise sobre esse fenômeno exige um olhar mais acurado.

Aparenta ser consenso na mídia o fato de o Brasil ter, no século XXI, assumido a posição de País de retorno e também receptor, como se observa numa reportagem de $\mathrm{O}$ Estadão publicada em 2012.

Revolução global. A ascensão dos países emergentes está revolucionando a imigração global. [...]. O Brasil está no meio desse redemoinho demográfico. Há duas décadas os brasileiros fugiam como os haitianos. Agora voltam. Estável, democrático, com uma economia em expansão [...]. Reeditando a história do século 19 e 20, o País escancara as portas para os imigrantes europeus, mas também para os latinos (O Estadão, Internacional, 08 jan. 2012, grifos nossos) $)^{2}$.

Diariamente são veiculados dados da chegada de novos migrantes e as mídias e redes sociais digitais se tornaram espaços para divulgação, além de promover debates sobre o tema. Um aspecto que tem chamado a atenção para vários estudiosos (PÓVOA NETO 2014; COGO e BADET, 2013 entre outros) são os termos empregados nas reportagens que estimulam a xenofobia, como a expressão destacada escancara.

Ao chamar o fenômeno de "revolução global" e comparar brasileiros e haitianos como tendo vivenciados "fugas" passa ao leitor a impressão que haitianos são fugitivos

\footnotetext{
${ }^{2}$ Disponível em: http://internacional.estadao.com.br/noticias/geral,brasil-novo-polo-de-imigracao-imp,819891 Acesso em: 03 abr. 2014.
} 


\section{SEMINÁRIO DE PESQUISA EM CIÊNCIAS HUMANAS - SEPECH \\ Humanidades, Estado e desafios didático-científicos \\ Londrina, 27 a 29 de julho de 2016}

como foram os brasileiros nas décadas de 1980/90, ou seja, desconsidera os contextos particulares de um e outro. A expressão escancara também demonstra uma ideia de ausência de política migratória restritiva e fica nítida essa ideia quando se usa o termo "mas também", parecendo ser este o problema que precisa vir a ser resolvido. O uso de termo como "escancara" denota ainda que o Brasil está aberto para receber quaisquer estrangeiros, como os "latinos", sem lhes impor limites.

É possível que o País esteja sim revivendo o boom migratório do final do século XIX, porém ainda não seria considerado recorde e nem significaria ser uma reedição do vivido no século XIX. Apontam os números: em todo o mundo há cerca de 250 milhões de imigrantes, menos de 1 milhão se encontra no Brasil (dados da Polícia Federal, 2012). O site OEstrangeiro.Org publicou em 22 de maio de 2013 um artigo atualizado do quantitativo de migrantes no País, que abrangiam todas as categorias e afirmou haver no Brasil menos de $0,4 \%$ da população migrante do mundo, e, em se tratando de refugiados, a concessão de vistos não alcançava 3.000/ano (Dados retirados de OEstrangeiro, 2013) ${ }^{3}$. Com referência à migração haitiana, em 2015, o governo concedeu residência permanente para 43,8 mil haitianos (BRASIL, 2015). O que se tem de herança daqueles séculos são as legislações restritivas e seletivas e não uma "revolução global". As mídias digitais ao exacerbar sobre esse novo fluxo migratório colaboram para a existência de manifestações discriminatórias contra os migrantes haitianos.

O Centro de Estudos das Relações de Trabalho e Desigualdades - CEERT ${ }^{4}$ traz em seu Portal 12 notícias de haitianos submetidos a discriminação em várias partes do País: "Alguns brasileiros tratam os haitianos como escravos', diz organização" (11 fev.2016); "Ao menos 500 haitianos já sofreram violência por racismo em MT" (12 dez. 2015); "Audiência pública na Câmara [São Paulo] debate os recentes ataques xenófobos no Brasil" (23 set. 2014); "Imigrantes haitianos sofrem racismo e xenofobia no Brasil" (15 maio 2014). O que se verifica, portanto, é que a partir de 2010 com o novo panorama migratório no Brasil, o País assiste à chegada de "indesejáveis", pessoas "cuja visibilidade e interesse precisam ser constantemente negociadas por representarem exatamente as etnias indesejadas historicamente para povoar o país" (COGO e BADET, 2013, p.23, grifos nossos).

Os países, incluindo o Brasil, "sempre tentaram selecionar o tipo de imigrantes que queriam" e a imprensa cumpre seu papel no fortalecimento desse ideal (PÓVOA NETO, 2012). Analisando o contexto passado/presente parece haver ainda hoje um perfil "desejável" e outro "indesejável" explicitado nas políticas que regulamentam a migração e também em manifestações discursivas oficiais ou não.

A diferença é que atualmente convivem no País ambas as categorias (PATARRA e FERNANDES, 2011) e uma delas, a haitiana tem sido alvo de discursos desqualificadores, inclusive oficiais: "O Brasil tem conseguido atrair uma quantidade

\footnotetext{
${ }^{3}$ OESTRANGEIRO. ORG. Exclusivo: os números exatos e atualizados de estrangeiros no Brasil. 22 maio 2013. Disponível em: https://oestrangeiro.org/2013/05/22/exclusivo-os-numeros-exatos-eatualizados-de-estrangeiros-no-brasil-2 Acesso em 06 abr. 2014. Em nota de fim de página, o jornalista afirma "Os dados apresentados na matéria foram obtidos através de requerimentos feitos pelo e-Sic (sistema de informação ao cidadão), tendo os números de 2012 sidos requeridos ao Itamaraty e os números totais requeridos à Polícia Federal.

${ }^{4}$ CEERT. Busca \#haitianos. Disponível em http://www.ceert.org.br/no ticias/tag/haitianos Acesso em: 30 mar. 2014 e atualizado em 12 abr.2016.
} 


\section{SEMINÁRIO DE PESQUISA EM CIÊNCIAS HUMANAS - SEPECH \\ Humanidades, Estado e desafios didático-científicos \\ Londrina, 27 a 29 de julho de 2016}

grande de imigrantes, de haitianos e africanos, mas também de trabalhadores qualificados" (Presidente do CNIg em entrevista ao El País, Brasil, 08 jun.2015). Novamente, o uso do termo "mas também" aponta em direção a dois polos: de um lado migrante "qualificado", do outro, o "desqualificado", valendo-se das suas origens para a adjetivação.

Esse pensamento parece ser fruto de um passado cuja história foi racialmente construída, quando o pensamento social brasileiro se instituía em busca de se formar uma nação civilizada (MOORE, 2007; IANNI, 2004, Da MATA, 2010) e se perpetua e se consolida em comportamentos discriminatórios que fazem eco sejam nas notícias veiculadas nas mídias, sejam nos comentários que essas notícias despertam, cujos conteúdos são sentidos e vivenciados pelo migrante que também se manifesta: "A COR DA MINHA PELE NÃO DEFINE O MEU FUTURO”, brado de um jovem haitiano em sua página pessoal do Facebook $(2015)^{5}$.

\section{2. "A COR DA MINHA PELE NÃO DEFINE O MEU FUTURO"}

Uma jovem catarinense posta no Facebook (nov.2014) uma pergunta sobre o motivo porque haveria tantos haitianos "por metro quadrado" em Florianópolis, o que a deixara horrorizada. Recebeu mais de 130 respostas e grande parte falava sobre se tratar de questões políticas e conspiratórias. Uma delas dizia se tratar de medida para enfraquecer a identidade nacional.

Outra jovem escreve no Twitter:

Puxa vida, vc vai pro Haiti? Que legal! Eu não teria coragem de ir prum lugar com tanto preto. (out.2011).

Outro opina em uma notícia publicada no G1:

essa gente só vem trazer AIDS e roubar, aqui em SC tá cheio desses aí, enchem os hospitais, enchem as creches, enchem as ruas, porquices, e por aí vai, daí chegam e já ganham direito de votar aqui, e pra quem eles vão votar? (jan.2016).

Estas manifestações, dentre milhares de outras, são expostas diariamente nas mídias e redes sociais digitais e são objetos de nosso olhar. Estaria mesmo nossa soberania sendo ameaçada pela presença do migrante negro? Como argumentou, defendendo-se ao ser chamado de racista, o agressor de um haitiano (maio 2015) num posto de gasolina, na cidade de Canoas -RS, "não foi racista nem xenófobo, agiu por uma questão de "soberania nacional". Um dos vídeos no Facebook que mostrou o acontecimento recebeu mais de 9 mil compartilhamentos e vários comentários favoráveis à atitude do brasileiro. Por que esse medo em relação ao migrante negro (AZEVEDO, 1987) e não com migrantes brancos oriundos da América do Norte e da Europa Ocidental?

\footnotetext{
${ }^{5}$ Postagem feita por um jovem haitiano em 26 set. 2015 motivada por assassinatos contra haitianos no Brasil. Manteve-se as letras maiúsculas como na postagem
} 


\section{SEMINÁRIO DE PESQUISA EM CIÊNCIAS HUMANAS - SEPECH \\ Humanidades, Estado e desafios didático-científicos \\ Londrina, 27 a 29 de julho de 2016}

Compreende-se que um projeto de mestiçagem secularmente elaborado e que teve como resultado a categoria cor híbrida, o pardo (OSÓRIO, 2003), parece estar sendo ameaçado com a chegada de migrantes negros, oriundos de um país pobre. Assim como estaria também ameaçada a identidade nacional tão duramente perseguida e fortalecida no mito da democracia racial (IANNI, 2004; NOGUEIRA, 1985 entre outros) que forjou uma população branca/mestiça e civilizada. A entrada de migrantes negros muda a paisagem racial urbana e incomoda, horrorizando. Esse medo e horror, impostos contra os haitianos pelo mundo ocidental (SCARAMAL, 2006; SEITENFUS, 2014) tem sido a substância para esses comportamentos e que assusta o migrante, impelindo-o a um dizer angustiado ligando a cor de sua pele à definição seu futuro. Essa relação para o jovem haitiano é ininteligível.

Trabalha-se, nesse contexto, com categorias binárias, o "eu", brasileiro, aquele que se encontra estabelecido e que diz; e o "outro", migrante, haitiano, fora de seu lugar, sujeito contextualizado nesses dizeres. O que diz o "eu" sobre o "outro", aquele que chega e carrega em seu corpo a marca de ser migrante, de país pobre e negro, ou seja, aquele que carrega triplas marcas: migrante, negro, pobre? Para a visualização desses dizeres, buscou-se o ciberespaço (LEVY, 2000) como campo selecionado para coleta de dados e a metodologia se deu pela modalidade netnografia.

O pesquisador social revisitou a história da migração brasileira compreendendoa como processo social motivada pelo pensamento social brasileiro de cunho racialista (SEYFERTH, 2000, 2015 dentre outros) e foi instigado a refletir sobre manifestações discursivas postadas no ciberespaço, as quais foram vistas como fatos sociais concretos porque gerados e consolidados historicamente.

Os sentidos desses dizeres no contexto migratório são relevantes porque parecem trazer de volta uma memória esquecida, a do branqueamento no Brasil. Um possível enegrecimento à vista parece ter intensificado o medo e o ódio (FANON, 1968; MOORE, 2007) contra a população negra aliados agora à xenofobia. Desse modo, o racismo à brasileira (camuflado) é colocado a prova e as vozes racistas se tornam audíveis e visibilizadas em tons também xenófobos. Não se trata de somente um ódio a estrangeiros, e sim, a um determinado estrangeiro.

Meu avô sobre tragédias no Haiti: Preto geralmente quando nao caga na entrada, caga na saída. Já esses ai cagam nos dois' (Twitter, 17 fev. 2015).

haiti nao fica na africa mas eh tdo preto tdo farinha do mesmo saco (Twitter, 15 out. 2014)

Mais um \#ciclista assaltado em Ribeirão Preto. Foi pedalar e perdeu a bike. Até quando? Antes Califórnia brasileira, hoje Haiti!!! (Twitter, 14 jul.2014).

A migração contemporânea no Brasil, nessa conjuntura, a haitiana, é um fenômeno que precisa ser compreendido, assim como as reações desencadeadas. Este estudo, que envolveu relações entre sujeitos, requereu que fosse problematizado o aspecto ético. Refletiu-se, por conseguinte, que o comprometimento do pesquisador era com os sujeitos percebidos, os migrantes haitianos, e o silenciamento sobre os discursos de xenofobia, racismo e discriminação colocaria o investigador em estado de cumplicidade com os locutores, autores de seus dizeres, que carregam consigo habitus. 


\section{SEMINÁRIO DE PESQUISA EM CIÊNCIAS HUMANAS - SEPECH \\ Humanidades, Estado e desafios didático-científicos \\ Londrina, 27 a 29 de julho de 2016}

A noção bourdieusiana, compreende habitus como "disposições adquiridas pela experiência, logo, variáveis segundo o lugar e o momento" e "socialmente constituídas" (BOURDIEU, 2004, p.25). Assim, os olhares de brasileiros sobre sujeitos migrantes negros e pobres se configuram pelas disposições históricas e conforme estruturas sociais apreendidas. Logo, falamos do lugar que ocupamos, o qual é historicamente construído, e as palavras se colocam conforme nossas disposições, qualquer palavra dita conformase com o lugar social daquele que diz, isto é, cada pessoa vê o espaço onde habita de acordo com a sua posição naquele espaço (BOURDIEU, 2004).

Por isso, são habitus histórico-sociais apreendidos que permitem uns selecionarem outros, isto é, determinar quem eu quero no meu País. Cada dizer manifestado expressa o lugar social que o dizente ocupa, e isso está determinado pelo seu modo de ver o mundo.

Trazer à luz essas manifestações é assumir a percepção de que a "ciência social é um regime de poder que ajuda a normalizar a ordem social" (CHRISTIANS, 2006, p. 150). Se assim tem sido, é possível sê-lo também de outro modo, e este é um desafio na busca pela humanização das questões migratórias, pois um observador neutro possivelmente ignoraria as "relações de poder associadas ao gênero, [...], à etnicidade, à raça e à nacionalidade" (CHRISTIANS, ibidem), as quais estão cotidianamente expressas nos comportamentos.

Palavras de um haitiano sobre brasileiros:

Tinha um lugar do meu lado (no ônibus). Entrou gente, mas ninguém sentou do meu lado. Neste dia, eu fiquei muito triste, chateado. Daquele dia até hoje eu sinto a dor, fiquei envergonhado", desabafou o imigrante haitiano Joaquim Ansiote ao Caminhos da Reportagem. Quer saber como é ser imigrante africano e haitiano no Brasil? Assista na íntegra: http://bit.ly/1OosQT7

Palavras de um brasileiro sobre haitianos, em comentário numa reportagem de 23 de fev. de 2014, que foi noticiada em várias mídias nacionais "Haitiano é espancado até desmaiar no RS":

Será que ele volta para a sua casa depois dessa? Ou vai esperar acontecer coisa pior? Eu sou contra a violência, e também não tenho nada contra imigrantes. $O$ problema são aqueles que não tem nada a acrescentar ao nosso país, como os haitianos e os "cucarachos" bolivianos. Se eu pudesse dizer isso a ele, e ele pudesse me entender, eu iria dizer...

Manifestação de um aposentado residente em Brasiléia-Ac sobre crime de vilipêndio de cadáver ocorrido na cidade em 16 abr. 2013

Só pode ter sido coisa de haitiano"

Outro morador sobre a mesma questão também acusa os haitianos 


\section{SEMINÁRIO DE PESQUISA EM CIÊNCIAS HUMANAS - SEPECH \\ Humanidades, Estado e desafios didático-científicos \\ Londrina, 27 a 29 de julho de 2016}

"Ninguém sabe a procedência desse povo. Sabemos que o país deles tem epidemia de cólera, hepatite, aids. Eles não têm controle de nada, não fazem prevenção sexual."

Todas essas atitudes carregam em seu contexto a história do pensamento social brasileiro, cuja memória encontra-se ainda viva no século XXI.

\section{CONSIDERAÇÕES DO CONFRONTO ENTRE "EU" E O "OUTRO": "CADA UM, UM VALENTE"!}

Migrar é estabelecer uma determinada relação num campo de poder já vivenciado por um "eu" e que nele já se encontra estabelecido. O "eu”, que fala sobre o "outro", diz em conformidade com o lugar que ocupa. Esse processo precisa ser humanizado e a postura dos órgãos governamentais tem se mostrado contraproducente ${ }^{6}$, considerando que a legislação que ainda vigora para a recepção de migrantes é da década de 1980, quando o País atravessava a ditadura militar.

Notou-se que a chegada do migrante haitiano coloca por terra um projeto de nação branca, de olhos azuis, dita civilizada, o que tem sido vista como "ameaça nacional". A paisagem racial muda, enegrece, principalmente no Sul e no Sudeste, e as manifestações apontam para essa nova cor como um problema a ser resolvido.

É mister, pois, escrever uma nova página na história da migração brasileira, em que o "outro" "indesejável” se faça visível, e é nesse contexto que os pensadores sociais precisam atuar. Analisar a realidade brasileira e sugerir novas práticas e novos comportamentos para a nação brasileira é um dos desafios atuais. Compreender os processos interacionais entre brasileiro e haitiano, de modo que esse migrante seja visto como potencial de transformação social, como tem agido ao longo da história haitiana: sujeitos capazes de fazer a única revolução negra no mundo (JAMES, 2010), e que estudam mesmo sem recursos, como explana o jovem haitiano Alix Georges, que vive no Brasil desde 2006 e reside em Porto Alegre - RS "Nosso povo gosta muito de estudar. Haitiano estuda mesmo com fome e com poucos recursos" 7 .

Por fim, migrar é um direito humano e "devemos ver em cada um deles um valente. Alguém que subverteu a regra prevalecente no mundo. E o melhor que podemos fazer é nos colocar no lugar dele, estendendo-lhe a mão para que se torne um vitorioso" (VENTURA, 2016).

Progressivamente, a pirâmide racial tem invertido, há mais negros/as atores de processos de mudança, o que significa dizer que a paisagem sociorracial enegreceu, apontando para uma nova identidade racial brasileira: a negra e oriunda de um novo espaço geográfico: o Caribe. E com essa nova identidade é possível revisitar a

\footnotetext{
${ }^{6} \mathrm{O}$ que, não necessariamente, representa toda a esfera do Governo brasileiro. Referenciamos a ação de concessão de permanência, em 2015, a cerca de 43 mil haitianos, mas muito ainda há que se fazer para lhes conceder dignidade. Referenciamos também várias ações por parte de prefeituras municipais, com a de Contagem, em Minas Gerais que realiza projetos de inclusão das crianças haitianas em escolas municipais.

${ }^{7}$ Disponível em TERRA, EDUCAÇÃO "Nosso povo estuda mesmo com fome, diz haitiano que faz mestrado no RS”. Reportagem publicada em 26 abr. 2013. Disponível em:

$\mathrm{http}$ //noticias.terra.com.br/educacao/nosso-povo-estuda-mesmo-com-fome-diz-haitiano-que-fazmestrado-no-rs,09c43e6dae 24e310VgnVCM500000 9ccceb0aR CRD.html Acesso em vários momentos.
} 


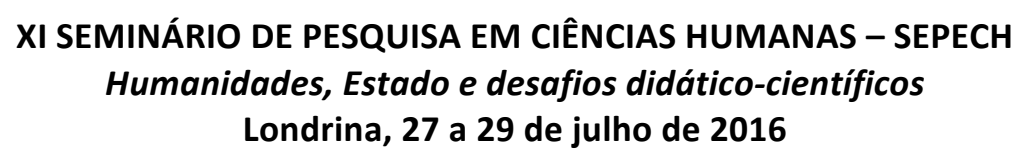

historiografia oficial a partir dos haitianos e da influência do Haiti na história do Brasil e trazê-la para o diálogo com a pesquisa social na atualidade. Urge encontrar soluções criativas e agir soberana e humanamente quando se trata de resolver os processos migratórios.

\section{REFERÊNCIAS BIBLIOGRÁFICAS}

AZEVEDO, Celia Maria Marinho de. Onda negra, medo branco: o negro no imaginário das elites — século XIX. Rio de Janeiro: Paz e Terra, 1987.

BOURDIEU, Pierre. Coisas ditas. Tradução Cássia R. da Silveira e Denise Moreno Pegorim. Revisão técnica Paula Montero. São Paulo: Brasiliense, 2004.

BRASIL. Decreto-Lei $\mathrm{n}^{\mathrm{o}}$ 406, de 4 de maio de 1938. Dispõe sôbre a entrada de estrangeiros no território nacional. Câmara dos Deputados, Brasília - D.F., Disponível em: http:/www 2.camara.leg.br/legin/fed/declei/1930-1939/decreto-lei-406-4-maio1938-348724-publicacaooriginal-1-pe.html Acesso em: 08 maio 2015.

. PORTAL. Brasil autoriza residência permanente a 43,8 mil haitianos. 11out. 2015. Disponível em: http://www.brasil.gov.br/cidadania-ejustica/2015/11/brasil-autoriza-visto-de-residencia-permanente-para-43-8-mil-haitianos Acesso em: 12 nov. 2015.

COGO, Denise Maria; SOUZA, Maria Badet. Guia das migrações transnacionais e diversidade cultural para comunicadores - Migrantes no Brasil. Bellaterra: Instituto Humaitas; Unisinos; Instituto de la Comunicación de la UAB, 2013. (Coleção: Guias De Diversidade Cultural Para Comunicadores).

CRISTIANS, Clifford G. A ética e a política na pesquisa qualitativa. In. DENZIN, Norman k. O planejamento da pesquisa qualitativa: teorias e abordagens. Tradução Sandra Regina Netz. Porto Alegre: Bookman, 2006. p.141-163.

DA MATA, Roberto. Relativizando: uma introdução à antropologia social. Rio de Janeiro: Rocco, 2010.

EL PAÍS. BRASIL. "É urgentíssimo aprovar a nova lei de imigração". Entrevista concedida ao Jornal pelo Presidente do Conselho Nacional de Imigração - CNIg, Paulo Sérgio de Almeida, em 08 jun. 2015. Disponível em http://brasil.elpais.com/brasil/20 15/05/28/politica/1432823272_043541.html Acesso em: 12 dez. 2015.

FANON, Franz. Os condenados da terra. Tradução de José Laurênio de Melo. Rio de Janeiro: Civilização Brasileira S.A.. 1968.

GORENDER, Jacob. A escravidão reabilitada. São Paulo: Ática, 1990. (Série Temas. Vol. 23. Sociedade e Política).

HUM HISTORIADOR BLOG. Carta "Invasão de haitianos?" ao Jornal O Globo. Por Hélion Póvoa Neto. 20 jan. 2014. Disponível em: 


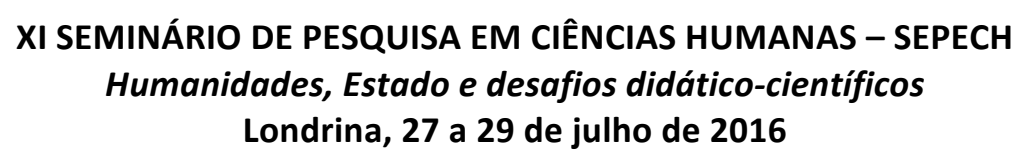

https://umhistoriador.wordpress.com/ 2014/01/20/invasao-de-haitianos/ Acesso em: 12 dez.21015.

INSTITUTO HUMANITAS UNISINOS. Migração: processo espontâneo é criminalizado. Entrevista especial com Helion Póvoa Neto. Entrevista. 16 maio 2012. Disponível em: <http://www.ihu.unisinos.br/entrevistas/509050-migracao-processoespontaneo-e-criminalizado-entrevista-especial-com-helion-povoa-neto $>$. Acesso em: 03 abr. 2015.

IANNI, Octávio. Dialética das relações raciais. In. Revista Estudos Avançados, 18 (50), 2004. p.21-30. Disponível em: <http://www.scielo.br/scielo.php?pid=S0103$40142004000100003 \&$ script $=$ sci_arttext $>$. Acesso em 03 abr. 2012.

JAMES, C. L. R. Os jacobinos negros. Tradução Afonso Teixeira Filho. São Paulo: Boitempo, 2010.

MOORE, Carlos. Racismo e sociedade: novas bases epistemológicas para entender o racismo. Belo Horizonte: Mazza edições, 2007.

NOGUEIRA, Oracy. Tanto preto quanto branco: estudos de relações raciais. São Paulo: T. A. Queiroz, Editor, 1985.

PATARRA, Neide Lopes; FERNANDES, Duval. Capítulo II Políticas públicas e migração internacional no Brasil. In. CHIARELO, Leonir Mario (Coord.). Las políticas públicas sobre migraciones y la sociedade civil en América Latina: Los casos de Argentina, Brasil, Colombia y México. New York: Scalabrini International Migration Network Inc. 2011. p.151-268.

. O Brasil: país de imigração?. In. Revista Eletrônica de Estudos Urbanos

e Regionais. Revista eletrônica@metropolis. N. 09. Ano 03. Jun. 2012. p.06-18. Disponível em: $\quad<$ http://www.emetropolis.net/index.php?option=com edicoes\&task=artigos \&id=31\&la ng=pt $>$. Acesso em: 26 mar. 2015.

SCARAMAL, Eliesse dos Santos Teixeira. Haiti: fenomenologia de uma barbárie. Goiânia: Cânone Editorial, 2006.

SEITENFUS, Ricardo. Haiti: dilemas e fracassos internacionais. Ijuí: Ed.Unijuí, 2014. (Coleção Relações Internacionais e globalização; 47).

SEYFERTH, Giralda. Pensamento social no Brasil: notas de aulas. Organização: Joana Bahia, Renata Menasche e Maria Catarina Chitolina Zanini. Porto Alegre: Letra \& Vida, 2015.

Colonização, imigração e a questão racial no Brasil. Revista USP. São Paulo, n.53, março/maio 2002. p. 117-149.

VENTURA, Deisy. Migrar é um direito. São Paulo: SESC. 02 fev. 2016. Disponível em http://www.sescsp.org.br/online/artigo/s/dFi\#/tagcloud=lista Acesso em 04 abr.2016. 